\title{
Dinâmica de nitrogênio e fósforo nas frações dissolvida e particulada em águas de um evento de chuva
}

\author{
Nitrogen and phosphorus dynamic in the dissolved and \\ particulate fractions in river water from rainfall episode
}

Mayara Powrosnek ${ }^{1}$, Caroline Kozak ${ }^{1}$, Luciane Lemos do Prado ${ }^{1}$, Cristovão Vicente Scapulatempo Fernandes ${ }^{1}$

${ }^{1}$ Universidade Federal do Paraná, Curitiba, PR, Brasil. E-mails: cpm.mayarap@gmail.com, carolkozak05@gmail.com, lulepr1074@gmail.com, cris.dhs@ufpr.br

Como citar: Powrosnek, M., Kozak, C., Prado, L. L., \& Fernandes, C. V. S. (2020). Dinâmica do nitrogênio e fósforo nas frações dissolvida e particulada em águas de um evento de chuva. Revista de Gestão de Água da América Latina, 17, e5. https://doi.org/10.21168/rega.v17e5

RESUMO: As chuvas levam ao aumento da vazão do corpo hídrico e ao consequente incremento de poluição por vias difusas devido ao carreamento de material particulado através do escoamento superficial. A forma como os elementos nitrogênio $(\mathrm{N})$ e fósforo $(\mathrm{P})$ se encontram no sistema aquático define o tipo de interações que podem ocorrer e as consequentes reações químicas inerentes em um corpo d'água. Neste contexto, o objetivo deste trabalho foi quantificar $\mathrm{N}$ e P nas formas dissolvida e particulada, em amostras de um evento de chuva, a fim de verificar em qual fração são predominantes. Foram testados os métodos de separação por filtração e centrifugação. A área de estudo foi a Bacia do Rio Barigui, em dois pontos de monitoramento na porção norte da bacia. Os resultados indicaram que o P está predominante na fração particulada, e que o N está predominante na fração dissolvida, devido às forças de interação e solubilidade desses elementos, respectivamente. Além disso, o método da filtração mostrou-se mais eficiente na separação das frações do que o método da centrifugação. Desta forma, o entendimento desta dinâmica corrobora com o determinado em legislação, contudo estratégias para controlar a poluição por vias difusas e seus impactos na qualidade da água devem ser refinadas para a melhoria dos instrumentos de gestão de recursos hídricos em especial no que concerne as frações que sejam, de fato, relevantes para o seu monitoramento.

Palavras-chave: Filtração; Centrifugação; Poluição Difusa; Qualidade da água.

ABSTRACT: Rainfall episodes increase river flow and consequently pollution by diffuse routes due to the transport of particulate through runoff. The nitrogen $(\mathrm{N})$ and phosphorus $(\mathrm{P})$ forms in the aquatic system defines the kind of interactions in which can occur and chemical reactions in the water body. In this context, the aim of this study was to quantify $\mathrm{N}$ and $\mathrm{P}$ in dissolved and particulate forms, in samples during a rainfall event, in order to verify in which fraction they are predominant. The separation methods by filtration and centrifugation were tested. The study area was the Barigui River, at two monitoring points in the northern portion of the watershed. The results indicated that $P$ is predominant in the particulate fraction, and that $\mathrm{N}$ is predominant in the dissolved fraction, due to the interaction forces and solubility of these elements, respectively. In addition, filtration method proved to be more efficient in separating fractions than centrifugation method. In this way, to understand this dynamic corroborates with what is determined by legislation however, strategies to control pollution through diffuse ways and their impacts on water quality must be refined to improve water resources management, especially with regard to fractions that are in fact relevant to your monitoring

Keywords: Filtration; Centrifugation; Diffuse Pollution; Water quality.

\section{INTRODUÇÃO}

Os episódios de chuva conduzem o aumento da vazão de um corpo hídrico e, consequentemente, favorecem o incremento de poluição por vias difusas devido ao carreamento de particulado pelo escoamento superficial. Este material particulado é composto por partículas de solo suspensas, matéria orgânica, e também substâncias de origem antrópica, como compostos químicos (industriais e agrícolas) e resíduos urbanos. Portanto, a natureza dos poluentes oriundas de vias difusas é

Recebido: Março 16, 2020. Revisado: Abril 30, 2020. Aceito: Maio 21, 2020. 
resultado direto da dinâmica de uso da terra, densidade populacional, geologia e frequência de precipitações, perda de vegetação, ocorrência de assoreamento, redução da infiltração e consequente aumento do escoamento superficial (Salgado, 2013; Silva \& Poleto, 2017). A intensidade e a duração de um evento de chuva influenciam na carga inserida de poluentes aos rios (Felice et al., 2018). Assim, entende-se que os efeitos antropogênicos em rios, córregos e reservatórios podem ser observados pelo incremento de nutrientes, metais e matéria orgânica dissolvida e particulada nos corpos hídricos, principalmente durante os eventos de precipitação (Dodds \& Smith, 2016; Lee \& Lautenbach, 2016; Smith et al., 2017).

A forma como elementos, por exemplo, $\mathrm{N}$ e $\mathrm{P}$ se encontram no sistema hídrico, na forma particulada ou dissolvida, define o tipo de interação (transporte ou reação) e seu processo de reações químicas em suas respectivas frações. De acordo com Baird \& Cann (2011), as concentrações de íons inorgânicos em solução são regidas por reações ácidos-bases e solubilidade, enquanto a matéria orgânica sofre reações redox (oxi-redução). Assim, para uma adequada tomada de decisão na gestão de recursos hídricos, torna-se importante avaliar a forma predominante em que o composto se encontra.

O nitrogênio é um dos elementos mais eletronegativos presentes na tabela periódica, apresenta raio atômico pequeno e ausência de orbitais d acessíveis. Devido à grande quantidade de estados de oxidação e a lentidão de suas reações termodinamicamente favoráveis, o nitrogênio pode ser considerado um elemento de caráter químico singular (Shriver \& Atkins, 2003). A decomposição da matéria orgânica (rica em nitrogênio orgânico) pela ação enzimática das bactérias disponibiliza o nitrogênio ao ambiente na forma amoniacal $\left(\mathrm{NH}_{3} / \mathrm{NH}_{4}{ }^{+}\right)$, tornando-o susceptível aos processos oxidativos, dependendo do teor de $\mathrm{O}_{2}$ no meio (Stein \& Klotz, 2016). As bactérias do gênero Nitrossomona são capazes de oxidar o nitrogênio amoniacal a nitritos ( $\left.\mathrm{NO}_{2}{ }^{-}\right)$e do gênero Nitrobacter, a nitratos $\left(\mathrm{NO}_{3}{ }^{-}\right)$, tornando a assimilação do elemento mais fácil aos seres vivos. Esse processo é chamado de nitrificação (MetCalf et al., 2003). O processo inverso também pode ser favorecido em condições anóxicas e é denominado desnitrificação. De acordo com Russel (1994), compostos inorgânicos de nitrogênio são raramente encontrados como minerais, pois grande parte desses é solúvel em água. Assim, entende-se como nitrogênio total a soma de todas as frações dissolvidas mais a fração em forma particulada.

O fósforo pertence ao grupo do nitrogênio na tabela periódica, porém é menos eletronegativo e possui raio atômico maior. Segundo Russel (1994), ao contrário do nitrogênio que é encontrado isoladamente, o fósforo ocorre na natureza principalmente associado a depósitos de rochas de fosfato $\left(\mathrm{Ca}_{3}\left(\mathrm{PO}_{4}\right)_{2}\right)$ e apatita $\left(\mathrm{Ca}_{5} \mathrm{~F}\left(\mathrm{PO}_{4}\right)_{2}\right)$ e compostos contendo fosfato de cálcio, pois seu ciclo biogeoquímico é sedimentar. Nas águas, o fósforo está presente sob as formas de fosfato $\left(\mathrm{PO}_{4}{ }^{3}\right)$, polifosfato e fósforo (Sperling, 1996). Os íons polifosfatos funcionam como agentes sequestrantes e formam complexos insolúveis em água. Também ocorre reação entre fósforo e cálcio, formando precipitados como $\mathrm{Ca}_{3}\left(\mathrm{PO}_{4}\right)_{2}$ e $\mathrm{Ca}_{5}\left(\mathrm{PO}_{4}\right)_{3} \mathrm{OH}$ (Baird \& Cann, 2011). Por contribuição antrópica, o fósforo é inserido no sistema pela intensificação das atividades de fertilização, mineração e, principalmente, efluentes industriais e esgotos domésticos (Sperling, 1996).

Portanto, uma vez que estes elementos estejam na forma dissolvida em um corpo hídrico, podem causar o decréscimo da qualidade da água. 0 nitrogênio favorece a diminuição de oxigênio dissolvido no meio, pelos processos de nitrificação (Stein \& Klotz, 2016), e o fósforo pode causar eutrofização em condições favoráveis (Sperling, 1996). Contudo, esses elementos podem estar agregados às partículas de acordo com as condições ambiente (como temperatura e $\mathrm{pH}$ ) reduzindo, assim, a disponibilidade e suas interações com o meio. Esses efeitos são regidos por processos físico-químicos de solubilidade, estabilidade de complexos e adsorção física e química (Shriver \& Atkins, 2003; Skoog et al., 2006; Baird \& Cann, 2011). Enquanto a formação dos complexos é regida pela estabilidade das interações eletrostáticas devido à competição entre as moléculas do solvente e o íon metálico (Shriver \& Atkins, 2003), a formação de precipitados é definida pela constante de solubilidade que sofre influência do $\mathrm{pH}$ e da temperatura do meio (Skoog et al., 2006).

Assim, o objetivo deste trabalho é quantificar $\mathrm{N}$ e $\mathrm{P}$ na forma dissolvida e particulada, em amostras de um evento de chuva, a fim de verificar em qual fração são predominantes. Uma vez que é observado um aporte considerável de sólidos em suspensão, foi testado e avaliado a otimização do processo de separação das frações líquida e sólida por meio da centrifugação das amostras, e comparada ao método da filtração (tradicionalmente utilizado). 0 entendimento da dinâmica destes elementos no corpo aquático durante os períodos de precipitação e em qual fração são predominantes, associadas ao tipo de uso e ocupação do solo, podem auxiliar na adequada aplicação dos instrumentos de gestão de recursos hídricos. 


\section{MATERIAIS E MÉTODOS}

\section{Área de Estudo}

A coleta de amostras foi realizada em dois pontos de monitoramento do Rio Barigui, separados por uma distância de $18 \mathrm{~km}$ de rio. 0 ponto BA1 está situado na cidade de Almirante Tamandaré (coordenadas 25ำ18,7720 S; 4917,7412 0), com área de drenagem de, aproximadamente $58 \mathrm{~km}^{2}$. Enquanto o ponto BA2 localiza-se ao norte da cidade de Curitiba (coordenadas 25ำ38,7519 S; 4930,3325 0), no Parque Tingui, com área incremental de, aproximadamente $46 \mathrm{~km}^{2}$, totalizando $104 \mathrm{~km}^{2}$ de bacia e $32,8 \mathrm{~km}$ de rio.

0 uso da terra nos dois pontos de monitoramento é diversificado, como pode ser observado na Figura 1 e detalhado na Tabela 1.0 uso preponderante da terra em ambos os pontos é a vegetação, contudo entre os dois pontos há um decréscimo de, aproximadamente $22 \%$ da área vegetada. Em contrapartida, há um aumento da área urbana residencial de cerca de 17\%, de pasto/solo exposto de 0,15\% e agricultura de 5\% (Ferreira, 2019). Tais mudanças refletem o aumento da urbanização a jusante do Rio Barigui e, consequentemente, a diminuição de área de vegetação, o que pode acarretar impactos negativos sob a qualidade da água.

Tabela 1 - Distribuição do uso da terra para os pontos de monitoramento BA1 e BA2

\begin{tabular}{|c|c|c|c|c|}
\hline Uso da Terra & BA1 $\left(\mathrm{km}^{2}\right)$ & $\begin{array}{l}\text { Área incremental entre } \\
\text { BA1 e BA2 }\left(\mathrm{km}^{2}\right)\end{array}$ & BA2 $\left(\mathrm{km}^{2}\right)$ & Mudanças (\%) \\
\hline Água & 0,41 & 0,40 & 0,81 & $\uparrow 0,16$ \\
\hline Área Urbana Residencial & 3,44 & 10,60 & 14,03 & $\uparrow 17,16$ \\
\hline Área Urbana Industrial & 0,84 & 0,59 & 1,43 & $\downarrow 0,16$ \\
\hline Pasto/Solo Exposto & 14,02 & 11,19 & 25,20 & $\uparrow 0,15$ \\
\hline Agricultura & 3,24 & 4,74 & 7,98 & $\uparrow 4,72$ \\
\hline Vegetação & 35,87 & 18,36 & 54,23 & $\downarrow 22,02$ \\
\hline Total & 57,81 & 45,87 & 103,68 & \\
\hline
\end{tabular}

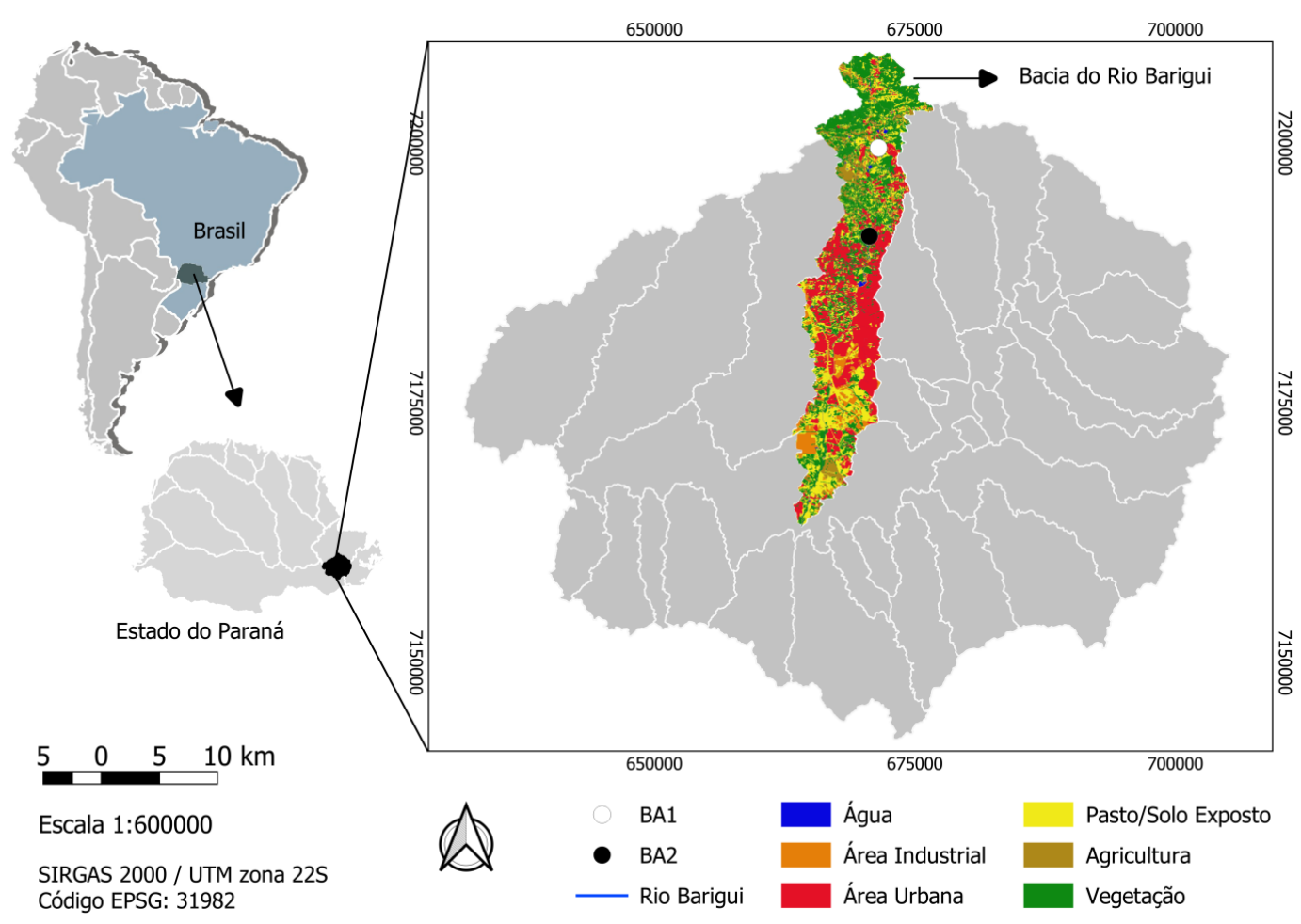

Figura 1: Pontos de estudo localizados na Bacia do Rio Barigui

Fonte: Adaptado de SUDERHSA (Instituto das Águas do Paraná, 2000), Ferreira (2019) e Kozak et al. (2019) 


\section{Coleta das amostras}

Foram coletadas amostras do rio, durante um evento de chuva, com o auxílio de amostradores automáticos, desenvolvidos por Braga (2013), instalados em cada ponto de monitoramento supracitado. A Figura 2 exemplifica o modo de coleta realizado. 0 equipamento é composto por um microprocessador MSP430, bomba de sucção de capacidade 6L/min e válvulas solenoides para distribuição das amostras coletadas, 24 garrafas de polietileno com capacidade de 1 litro e sensor de nível com resolução de 1 minuto. 0 sistema é operado por um código em linguagem $\mathrm{C}$, que identifica a variação do nível da coluna d'água a partir de um gatilho inicial. Foram utilizadas as variações iniciais de $5 \mathrm{~cm}$ em 10 minutos para o ponto BA1 e $6 \mathrm{~cm}$ em 8 minutos para o ponto BA2, devido às diferentes características das respectivas seções transversais, em cada ponto de monitoramento. 0 ponto BA1 possui seção mais estreita, onde as variações de nível d'água são facilitadas, enquanto no ponto BA2, a seção é mais larga (mais detalhes são apresentados no Apêndice A deste trabalho). Após o gatilho inicial, uma nova amostra é coletada com o acréscimo ou decréscimo de $10 \mathrm{~cm}$ da coluna d'água. Esse tipo de amostragem permite a discretização temporal de um hidrograma, sendo possível captar sua variação quali-quantitativa simultaneamente em sequência temporal, como realizado em Kozak et al. (2019). As informações de chuva foram coletadas em estações pluviométricas próximas aos locais de monitoramento. Os dados de nível foram convertidos em vazão de acordo com a respectiva curva de descarga de cada seção, apresentados no Apêndice A deste trabalho.

Todas as garrafas de polietileno utilizadas para a coleta de amostras foram previamente descontaminadas em ácido clorídrico 5\%. 0 amostrador não possui sistema de refrigeração, portanto, as amostras foram armazenadas a temperatura $\sim 4^{\circ} \mathrm{C}$ apenas após chegada ao laboratório. No entanto, as questões relacionadas as potenciais limitações analíticas como temperatura de coleta, refrigeração e/ou preservação das amostras e tempo de translado campo-laboratório foram analisados em planejamento experimental, detalhados em Kozak (2016). Complementarmente, Powrosnek et al. (2019) demonstram que a variação das frações ao longo do tempo em amostras coletadas, nos mesmos pontos, em temperatura ambiente e refrigerado em plano experimental similar. Além disso, ressalta-se que aqui estão sendo avaliadas as quantidades totais de nitrogênio e fósforo, as quais não devem variar significativamente ao longo do tempo.

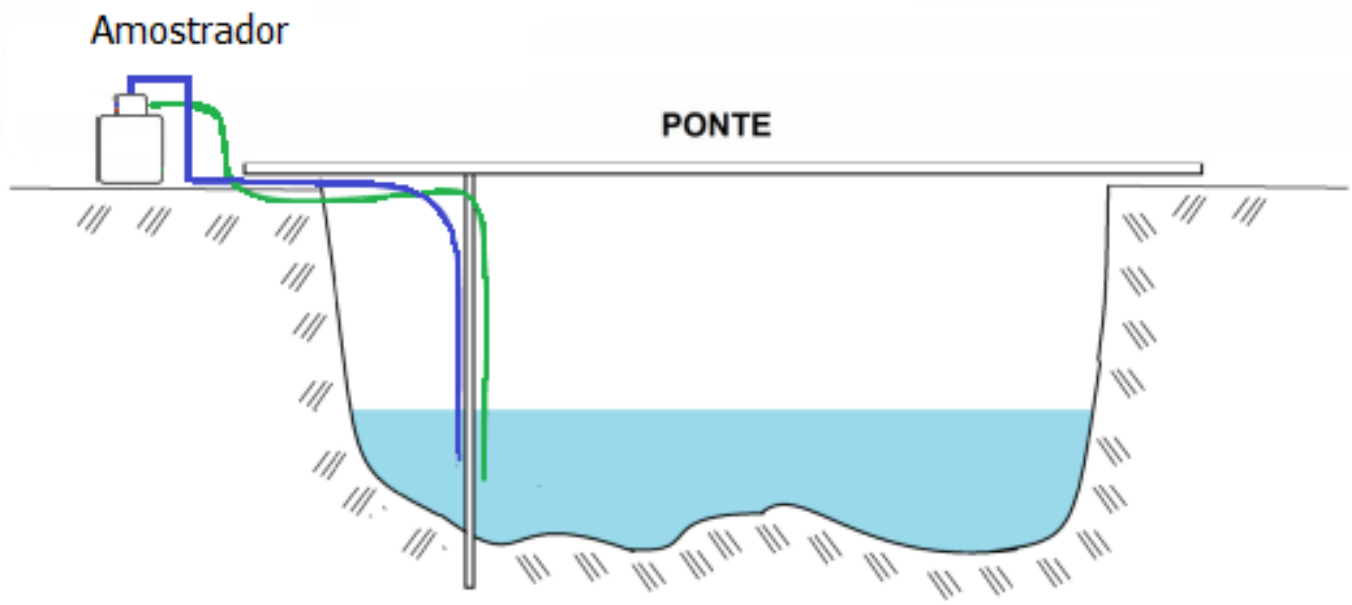

— Tomada das amostras Sensor de Nivel

Figura 2 - Representação esquemática da coleta de amostras por amostrador automático operado por variação de nível. Fonte: Adaptado de Braga (2013)

\section{Preparo das amostras}

Para cada amostra, foram separadas alíquotas de $10 \mathrm{~mL}$ para a análise de nitrogênio e de $25 \mathrm{~mL}$ para análise de fósforo, de acordo com American Public Health Association (2012). A Figura 3 ilustra o procedimento de separação das alíquotas, nas formas dissolvida e particulada por filtração e centrifugação. Uma das alíquotas foi submetida ao processo de filtração em membrana de acetato de 
celulose com porosidade de $0,45 \mu \mathrm{m}$ e a outra, ao processo de centrifugação (5400 rpm por 10 minutos). Com esse processo foram separadas as frações particulada e dissolvida por filtração e por centrifugação.

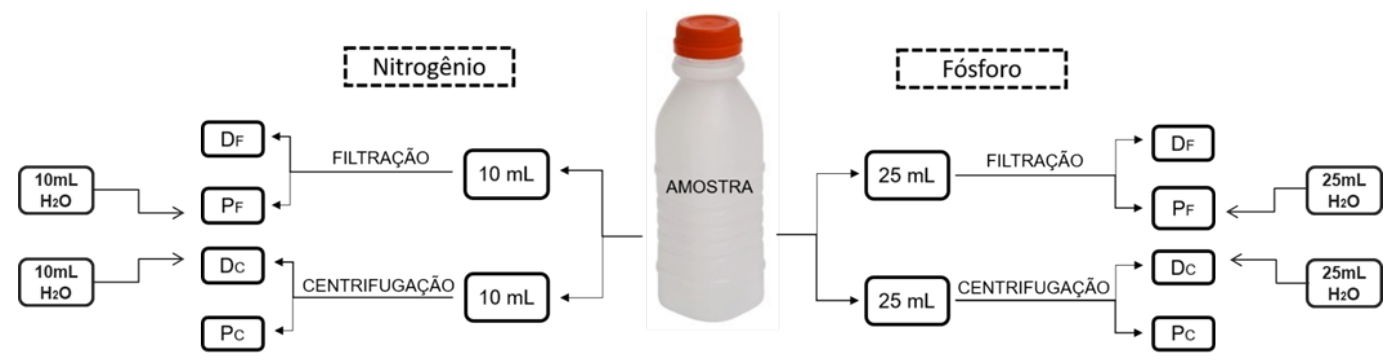

Figura 3: Separação das alíquotas dissolvida e particulada.

As frações analisadas foram identificadas como: (a) DF referente à alíquota da fração dissolvida após filtração em membrana de 0,45 $\mu \mathrm{m}$, (b) PF ao particulado retido no filtro de 0,45 $\mu \mathrm{m}$, (c) Dc corresponde a fração dissolvida, ou correspondente ao sobrenadante da alíquota centrifugada e (d) Pc ao particulado ou sólido decantado do centrifugado.

Para cada fração, foram analisados os parâmetros nitrogênio total e fósforo total. As amostras de N seguiram os métodos de Digestão por Persulfato (4500-N - C), seguido por redução em coluna de $\mathrm{Cd}-\mathrm{Cu}$ (4500- $\mathrm{NO}_{3}$ - E) e então quantificado pelo método colorimétrico (4500-NO2 - B), como determinado por American Public Health Association (2012) para a quantificação colorimétrica de N. Para o P, foi utilizado o método proposto por Prado (2015), disponível em Cipriano et al., (2019), para digestão das amostras, seguido pelo método colorimétrico do ácido ascórbico (4500-P - E) proposto por APHA (American Public Health Association, 2012). Este procedimento foi adotado para as seis amostras coletadas tanto no ponto BA1 como no BA2. Todos os ensaios foram realizados em triplicata. Para as análises de $\mathrm{P}_{\mathrm{F}}$, os ensaios foram realizados junto ao filtro de membrana de acetato de celulose onde o sólido ficou retido. Para eliminar quaisquer interferências, foi realizada análise da membrana sem amostra para controle de branco. Os limites de detecção (LD) e quantificação (LQ) para os métodos foram calculados usando as Fórmulas 1 e 2 abaixo (Skoog et al., 2006):

$$
\begin{aligned}
& L D=3 \frac{\sigma_{\text {branco }}}{\alpha_{\text {CurvaCalibração }}} \\
& L Q=10 \frac{\sigma_{\text {branco }}}{\alpha_{\text {CurvaCalibração }}}
\end{aligned}
$$

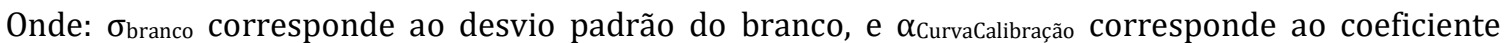
angular da curva de calibração ajustada para quantificação do elemento. As curvas de calibração e cálculo dos limites estão apresentadas no Apêndice A deste trabalho.

\section{RESULTADOS E DISCUSSÃo}

\section{Hidrogramas}

O evento de chuva ocorreu em Outubro de 2018, coletando amostras simultaneamente nos pontos BA1 e BA2 (Figura 4). Foram identificadas três contribuições intermitentes de precipitação, em ambos os pontos de monitoramento. Para o ponto BA1, as duas primeiras precipitações $(6 \mathrm{~mm}$ e $8,4 \mathrm{~mm}$, respectivamente) contribuíram para a infiltração da água do solo, e então, na terceira precipitação $(15,4 \mathrm{~mm}$, mais intensa que as demais) houve a variação de coluna d'água, acarretando uma diferença de vazão de $2,84 \mathrm{~m}^{3} / \mathrm{s}$ (vazão inicial de $0,36 \mathrm{~m}^{3} / \mathrm{s}$ e vazão de pico de $3,20 \mathrm{~m}^{3} / \mathrm{s}$ ). No ponto BA2, apenas a precipitação de 4,2 mm contribuiu para o processo de infiltração, enquanto a precipitação de $15,7 \mathrm{~mm}$ foi suficiente para o aumento significativo da coluna d'água, seguido da precipitação de 7,9 mm que acarretou nas principais variações de vazão (vazão inicial de $1,23 \mathrm{~m}^{3} / \mathrm{s}$ e vazão de pico de $1,81 \mathrm{~m}^{3} / \mathrm{s}$ ), visto que o solo já estava saturado. Tais detalhes de assimilação da chuva podem estar relacionados com o tipo de uso da terra. No ponto BA1 há mais porções de área vegetada, as quais contribuem melhor para a infiltração da 
água no solo, enquanto no ponto BA2, há mais porções de área urbanizadas, favorecendo o escoamento superficial. Em ambos os pontos de monitoramento foram escolhidas 6 amostras que representam a ascensão e recessão do hidrograma.

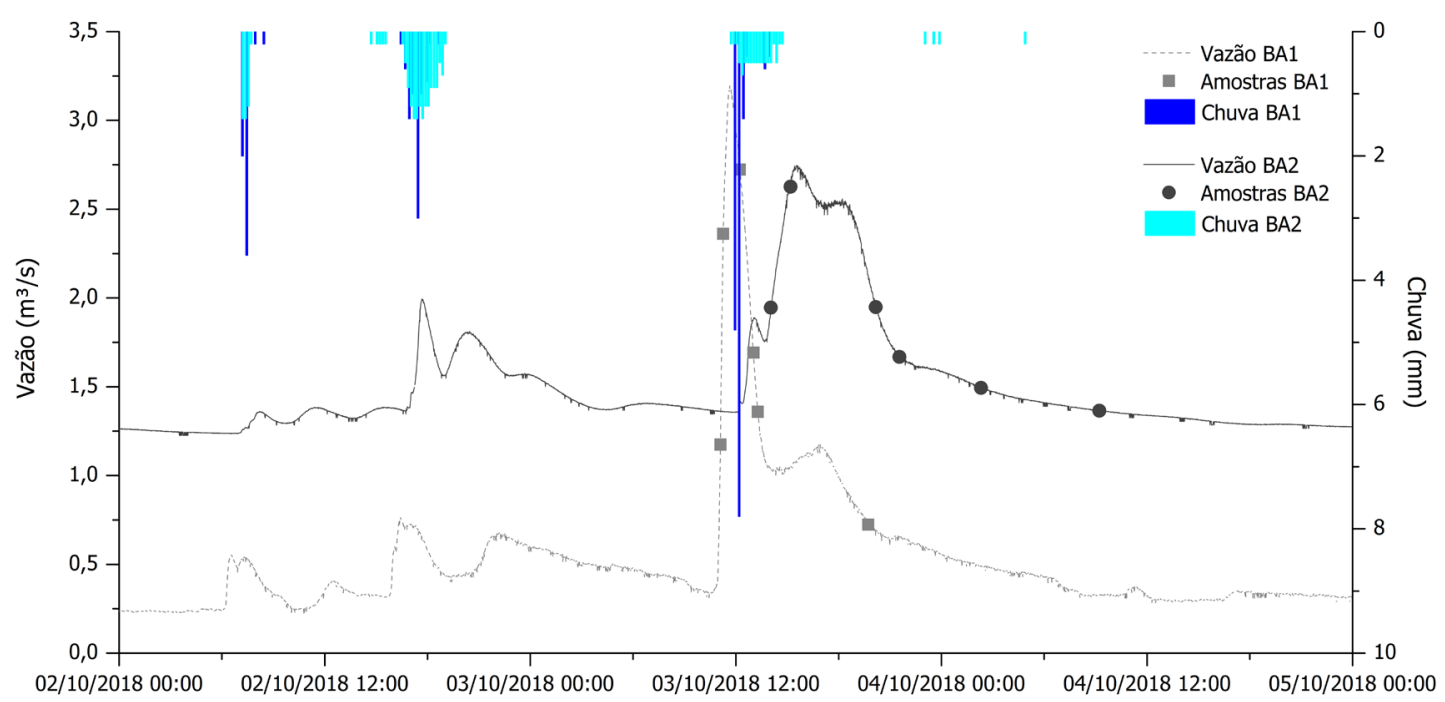

Figura 4. Hidrograma de coleta dos pontos BA1 (linha pontilhada) e BA2 (linha contínua). As linhas correspondem a vazão $\left(\mathrm{m}^{3} / \mathrm{s}\right)$, as barras correspondem à chuva $(\mathrm{mm})$ e os pontos correspondem às amostras coletadas.

\section{Comparação dos métodos de separação por centrifugação e filtração}

A Tabela 2 mostra os valores médios das concentrações de N e P para as amostras nas frações dissolvidas e particuladas usando os métodos de separação por centrifugação e filtração. A predominância de P foi observada nas frações particuladas em ambos os métodos de separação. Já o $\mathrm{N}$ foi predominante nas frações dissolvidas, bem determinado apenas pelo método de filtração. Para a separação do N, o método da centrifugação não apresentou proporções similares de separação, como ocorreu para o P. Isto pode indicar que para a devida separação do N, seja necessário um ajuste analítico, aumentando o tempo de exposição da amostra às forças gravitacionais da centrifugação.

Tabela 2 - Valores médios ( \pm desvio padrão) de N e P das amostras do evento de chuva para os pontos BA1 e BA2, na fração dissolvida e particulada nos métodos de separação por filtração e centrifugação

\begin{tabular}{|c|c|c|c|c|c|}
\hline Pontos & $\begin{array}{c}\text { Concentração } \\
\text { (mg/L) }\end{array}$ & $\mathbf{D F}_{\mathrm{F}}$ & $\mathbf{P F}_{\mathbf{F}}$ & Dc & $\mathbf{P c}_{\mathbf{C}}$ \\
\hline \multirow{2}{*}{ BA1 } & $\mathrm{N}$ & $3,13 \pm 1,03$ & $0,42 \pm 0,47$ & $2,99 \pm 0,72$ & $1,15 \pm 0,67$ \\
\hline & $\mathrm{P}$ & $0,04 \pm 0,01$ & $0,80 \pm 0,35$ & $0,06 \pm 0,03$ & $0,93 \pm 0,41$ \\
\hline \multirow{2}{*}{$\mathrm{BA} 2$} & $\mathrm{~N}$ & $3,55 \pm 0,64$ & $0,67 \pm 0,77$ & $1,73 \pm 0,30$ & $2,60 \pm 0,80$ \\
\hline & $\mathrm{P}$ & $0,07 \pm 0,02$ & $1,33 \pm 0,43$ & $0,17 \pm 0,08$ & $1,72 \pm 0,66$ \\
\hline
\end{tabular}

Nota: LD nitrogênio: 0,004 mg/L; LD fósforo: 0,005 mg/L; LQ nitrogênio: 0,012 mg/L; LQ fósforo: 0,018 mg/L.

A predominância de $\mathrm{P}$ nas frações particuladas foi observada em todas as amostras do evento, em ambos os pontos de monitoramento (Figura 5), e um acréscimo nas concentrações de P entre os pontos de monitoramento. Foi observado um percentual de 5\% do P na fração dissolvida e 95\% na fração particulada, quando utilizado o método da filtração, no ponto BA1 e no ponto BA2. Para o método da centrifugação, o percentual de 6\% do P está na fração dissolvida e 94\% na fração particulada para o ponto BA1, enquanto no ponto BA2 o percentual de 9\% de P está na fração dissolvida e 91\% na fração particulada. 

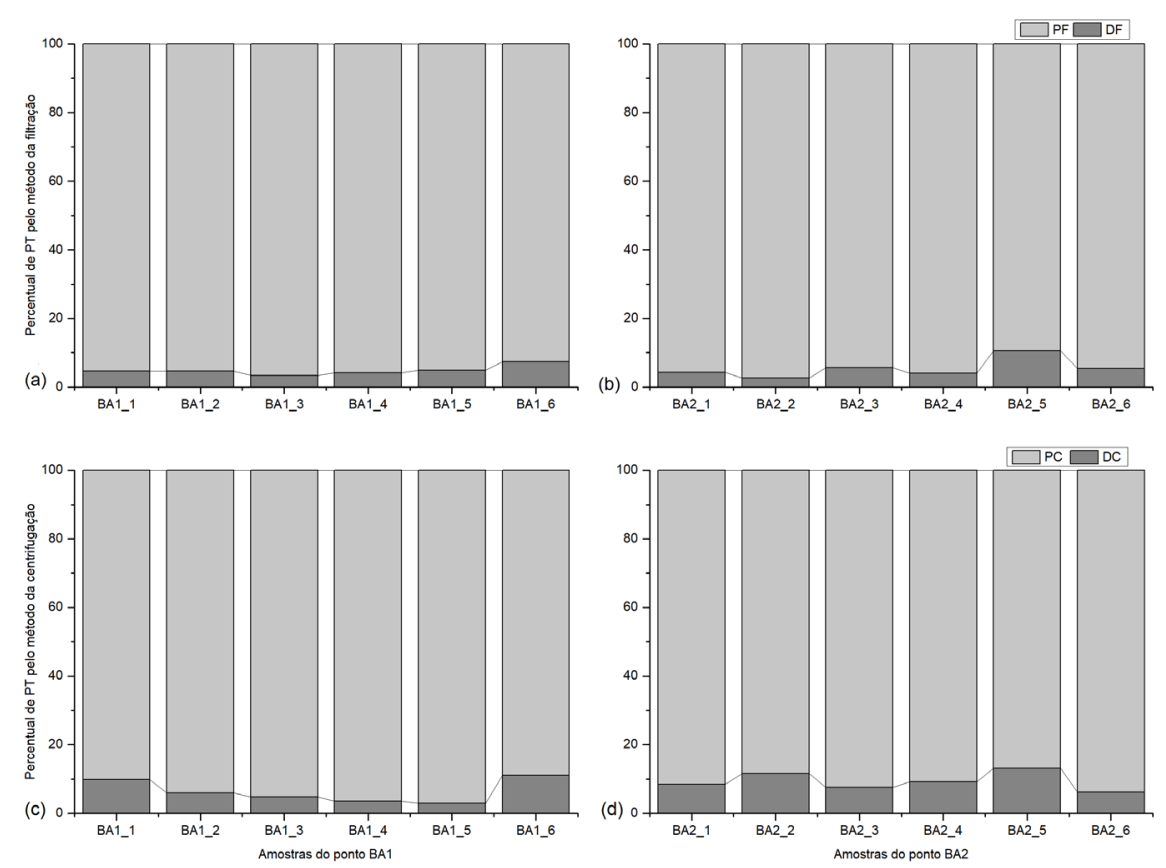

Figura 5: Distribuição percentual de P nas frações dissolvida e particulada: (a) ponto BA1 submetida ao processo de filtração, (b) ponto BA2 submetida ao processo de filtração, (c) ponto BA1 submetida ao processo de centrifugação e (d) ponto BA2 submetida ao processo de centrifugação.

Assim, os resultados encontrados apresentam poucas variações entre os dois métodos utilizados, independente do ponto de monitoramento. Esse resultado é reforçado por Rattan et al. (2019) que associam maiores concentrações de fósforo aderido ao particulado, vinculados às maiores cargas de sólidos. Tais cargas estão diretamente relacionadas aos períodos mais chuvosos, devido ao escoamento superficial que permite um carreamento mais intenso desses sólidos no corpo hídrico. Fato este também observado em Kozak et al. (2019). Neste sentido, Baird \& Cann (2011) relatam que as partículas mais finas dos sólidos em suspensão $(<63 \mu \mathrm{m})$ denominadas argilas, possuem grandes áreas superficiais, o que permite as interações com o fósforo. Além disso, estas interações estão relacionadas com a disponibilidade destes elementos minerais no meio (Mbabazi et al., 2019).

Os resultados encontrados nesse estudo corroboram com a afinidade que o elemento fósforo tem pela formação de precipitados, portanto, aderência às frações particuladas. Além disso, há o favorecimento para a formação de complexos insolúveis com íons polifosfatos e precipitados de sais de fósforo e cálcio, como $\mathrm{Ca}_{3}\left(\mathrm{PO}_{4}\right)_{2}$ e $\mathrm{Ca}_{5}\left(\mathrm{PO}_{4}\right)_{3} \mathrm{OH}$ por exemplo, e formação de agregados de partículas coloidais com hidróxidos gelatinosos de alumínio e ferro (Baird \& Cann, 2011). Kraal et al. (2017) identificaram a precipitação de fosfato de cálcio associado ao acúmulo de $\mathrm{HPO}_{4}{ }^{2-}$ em quantidades milimolares de cálcio e a adsorção de fosfato em calcita $\left(\mathrm{CaCO}_{3}\right)$ e, também, a precipitação de $\mathrm{Fe}(\mathrm{II})-\mathrm{P}$ como a vivianita, $\mathrm{Fe}(\mathrm{II})_{3}\left(\mathrm{PO}_{4}\right)_{2} \cdot 8 \mathrm{H}_{2} \mathrm{O}$.

Em contrapartida, as concentrações totais de N (fração dissolvida + particulada) foram similares em ambos os pontos de monitoramento, com diferenças somente entre os métodos de separação, como comentado anteriormente e exemplificado na Figura 6. Contudo, diferenças entre os métodos de separação foram observadas, como por exemplo, na amostra BA1_2 foi quantificado 2,79 mg/L de N na fração DF e 3,08 $\mathrm{mg} / \mathrm{L}$ na fração $\mathrm{D}_{\mathrm{C}}$, e na amostra BA2_1 foi quantificado 3,60 mg/L na fração $D_{\mathrm{F}}$ e $1,87 \mathrm{mg} / \mathrm{L}$ de $\mathrm{N}$ na fração $\mathrm{D}_{\mathrm{c}}$. Em média, as diferenças entre os métodos de separação para a quantificação de $\mathrm{N}$ foi de $0,14 \mathrm{mg} / \mathrm{L}$ no ponto BA1 e 1,82 mg/L no ponto BA2 (detalhes sobre os valores quantificado são apresentados no Apêndice A deste trabalho). Tais diferenças de concentração podem estar associadas às diferenças de uso do solo entre os pontos de monitoramento, que implicam em características moleculares distintas em compostos contendo o $\mathrm{N}$ e que interferem nos processos de separação. As amostras do ponto BA1 possuíam aspecto terroso característico de um local mais vegetado, podendo ser relacionado com solo erodido. Já as amostras do ponto BA2 possuíam um aspecto asfáltico característico de uma área de drenagem mais urbanizada, podendo estar relacionado com a lavagem superficial de ruas e calçadas.

No ponto BA1, pelo método da filtração, observou-se em média $88 \%$ do $\mathrm{N}$ na fração dissolvida e $12 \%$ na fração particulada, enquanto pelo método da centrifugação, $72 \%$ do $\mathrm{N}$ estava na fração dissolvida e $28 \%$ na fração particulada. Para o ponto BA2, o método da filtração teve valores similares 
ao BA1, com $86 \%$ do $\mathrm{N}$ na fração dissolvida e $14 \%$ na fração particulada. Contudo, no método da centrifugação, os percentuais médios foram distintos, com $41 \%$ do $\mathrm{N}$ na fração dissolvida e $59 \%$ na fração particulada.
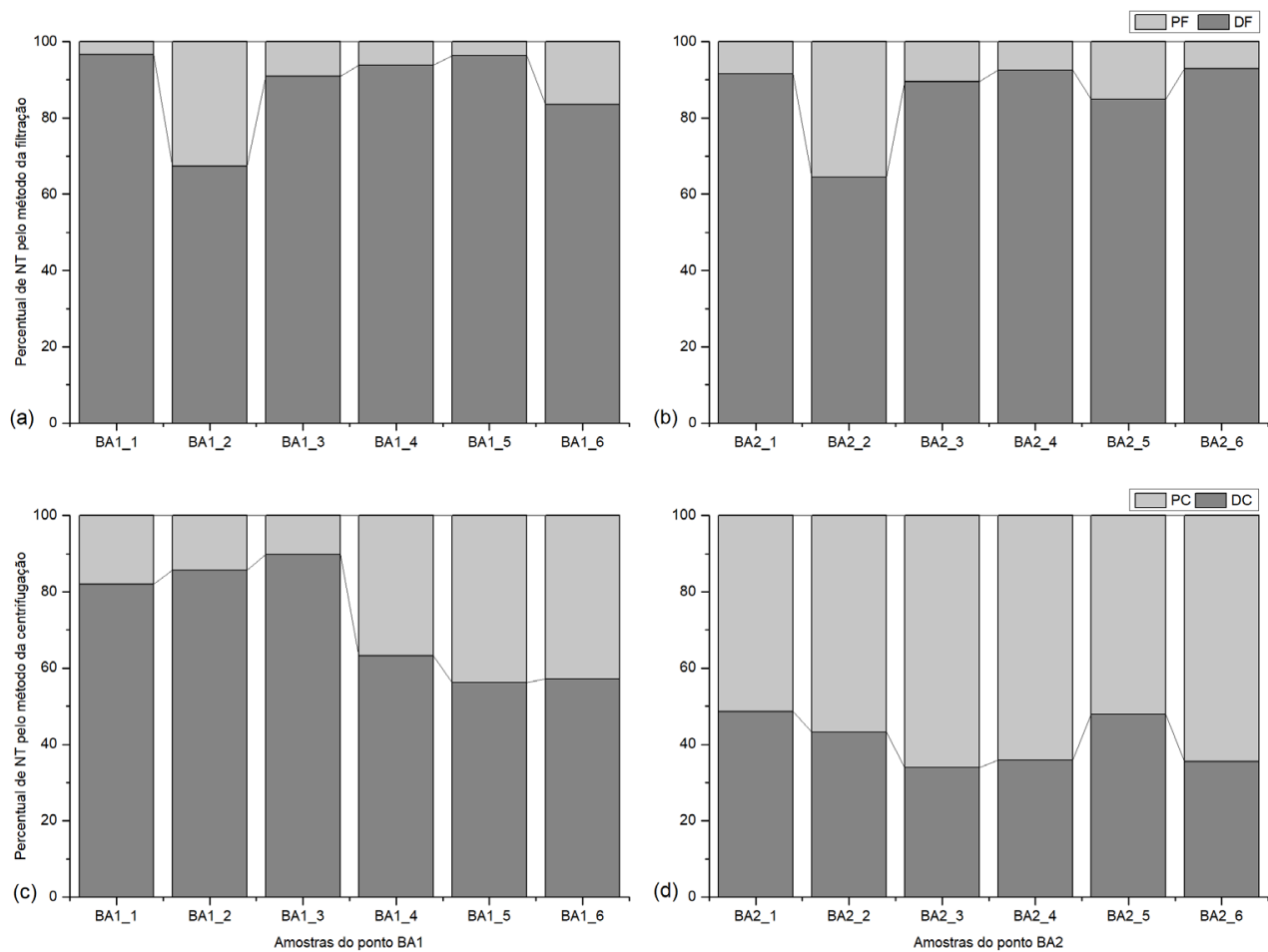

Figura 6: Distribuição percentual de $\mathrm{N}$ nas frações dissolvida e particulada: (a) ponto BA1 submetida ao processo de filtração, (b) ponto BA2 submetida ao processo de filtração, (c) ponto BA1 submetida ao processo de centrifugação e (d) ponto BA2 submetida ao processo de centrifugação.

A maioria dos compostos de nitrogênio é solúvel em água (Russel, 1994). Portanto, é esperado que a maior fração do elemento $\mathrm{N}$ encontre-se na forma dissolvida devido à estabilidade e lentidão de suas reações químicas (Shriver \& Atkins, 2003), corroborando com a distribuição encontrada neste estudo.

A quantificação de N e P nas frações dissolvida e particulada teve distribuição similar nas 12 amostras avaliadas quando foi utilizado o método da filtração, ou seja, maiores percentuais de P na fração particulada e de $\mathrm{N}$ na fração dissolvida. Contudo, as distribuições sofreram maiores variações quando usado o método da centrifugação. Tais condições podem estar associadas à eficiência do processo de centrifugação com amostras de características distintas. Segundo Chini et al. (2018) a força gravitacional e o tempo a que a amostra é submetida influenciam na eficiência da separação das espécies. Ao avaliar a eficiência de separação de nitrogênio, fósforo e carbono em diferentes tempos e velocidades de centrifugação, os autores avaliaram que a taxa de separação é proporcional ao tempo e a força a que as amostras são submetidas. Assim, as maiores eficiências foram observadas nas maiores velocidades e, portanto, maior oferta de força gravitacional, e com submissão ao processo por tempos mais longos.

Isso implica que o tempo e força ofertados no processo de centrifugação desse estudo podem não ter sido suficientes para levar a uma separação homogênea entre as amostras dos pontos BA1 e BA2, visto que o processo está sujeito a um equilíbrio de forças e as moléculas apresentam características diversificadas e, portanto, interações diferentes. De forma contrária, a amostra que é submetida ao processo de filtração induz obrigatoriamente a passagem do fluído por um meio permeável (membrana de acetato de celulose) capaz de reter as partículas, separando a fração líquida da fração sólida de forma equivalente e limitada pelo tamanho das partículas.

Assim, pressupõe-se que as mesmas partículas que ficaram retiradas no filtro durante o processo da filtração, poderiam ter permanecido em suspensão se submetidas ao processo da centrifugação, devido à insuficiente oferta de força gravitacional para aglomerá-las, como o observado durante as análises de N. Ressalta-se assim a relevância e precisão dos processos de filtração na separação de alíquotas de interesse, em frações dissolvidas e particuladas. Além disso, é válido mencionar que quando se faz necessário o uso da técnica de centrifugação ou só se tem esta opção, é necessário que a 
operação seja moldada de acordo com o tipo de amostra analisada. Por exemplo, é possível aumentar a velocidade e/ou o tempo de rotação, bem como diminuir ou aumentar o volume da alíquota e realizar ensaios em réplica para adequada otimização do processo.

\section{Na Aplicação à Gestão de Recursos Hídricos}

A resolução CONAMA n 357 de 17 de março de 2005 (Brasil, 2005), que dispõe sobre a classificação dos recursos hídricos e dá condições e padrões de lançamento de efluente, determina o monitoramento do fósforo em sua fração total (dissolvido + particulado) e das frações dissolvidas de nitrogênio, nas formas amoniacal, nitrito e nitrato. Neste caso, a distribuição encontrada neste trabalho corrobora com o indicado em legislação. 0 fósforo com maior afinidade pelo particulado requer uma análise que englobe essa fração, como acontece na análise de fósforo total. Enquanto o nitrogênio, predominante na forma dissolvida, deve ser avaliado com foco nas frações em solução: formas amoniacal, nitrito e nitrato.

Quando o composto está aderido ao particulado, como o $\mathrm{P}$, a interação com outros elementos se dá por disputas entre íons que compõem o particulado e os íons em solução, prevalecendo os compostos de maior estabilidade no equilíbrio (Skoog et al., 2006). Em contrapartida, quando o composto está dissolvido em solução, como o N, os íons estão mais disponíveis à interação com outros íons em solução podendo contribuir para o decréscimo da qualidade da água. Essa dinâmica está relacionada essencialmente as características dos íons e/ou moléculas. A análise das frações do N, que está majoritariamente dissolvido, tem grande impacto na gestão de recursos hídricos. Sperling (1996) defende que a forma orgânica ou amoniacal $\left(\mathrm{NH}_{3} / \mathrm{NH}_{4}{ }^{+}\right)$está associada a uma poluição mais recente, enquanto o nitrato representa uma poluição mais remota, visto que está relacionado aos estágios finais de oxidação no ciclo do N. Ainda, Piveli \& Kato (2006) indicam que o elevado teor de nitrogênio amoniacal em corpos hídricos está associado à proximidade de esgotos sanitários acarretando em um processo de decomposição recente.

A identificação da fração em que o elemento é predominantemente encontrado favorece a devida aplicação dos instrumentos de gestão de recursos hídricos no que concerne os efeitos poluidores, como plano de gestão direcionado à aportes específicos de poluentes, classificação dos corpos hídricos, sistema integrado e robusto de banco de dados uniforme. Da mesma forma, entende-se que tais caracterizações auxiliam na melhoria destes instrumentos já existentes e na inserção de novas medidas de controle e gestão dos recursos hídricos, como o aperfeiçoamento do entendimento da poluição difusa, por exemplo.

Assim, outro ponto a se considerar é que as medidas de qualidade da água analisadas foram determinadas durante um episódio de chuva, o qual não possui impactos na qualidade da água totalmente previstos e/ou determinados na legislação brasileira. Cabe ressaltar que os eventos de precipitação favorecem o aporte de material particulado em rios, e que há também a introdução de compostos dissolvidos, que podem exercer influência negativa na qualidade da água dos rios, a curto e longo prazo. Dessa forma, entender esta dinâmica dos nutrientes é fundamental na efetiva aplicação dos instrumentos de gestão dos recursos hídricos. São necessários avanços no monitoramento da contribuição por vias difusas e nas vazões com frequência de 5\% de ocorrência, pois são durante tais episódios que ocorrem grandes aportes de carga no rio. Assim, estratégias de redução dos impactos na qualidade da água podem ser determinadas, bem como a incorporação de medidas de controle ou BMPs (do inglês best management practices).

\section{CONSIDERAÇÕES FINAIS}

Considerando a aplicação das técnicas de separação das frações, foi possível observar que o método da filtração é favorecido pela indução forçada de um fluído através de uma membrana, evidenciando uma separação definida e similar entre as frações para ambos os pontos de monitoramento. Já o método da centrifugação mostrou-se mais sensível a erros sistemáticos inerentes às características do método de separação, como velocidade de centrifugação e tempo de exposição à força gravitacional. Neste caso, as separações não foram definidas e similares como o observado no outro método. Isso se deve às diferenças de força de separação: enquanto a filtração induz obrigatoriamente a passagem da amostra por uma membrana, a centrifugação exige força gravitacional, que pode variar em função do tipo de amostra, para a devida aglomeração das partículas.

Assim, foi possível quantificar as maiores concentrações de fósforo na fração particulada e de nitrogênio da fração dissolvida, devido respectivamente a maior afinidade iônica às partículas e maior solubilidade em água. Essa distribuição ressalta a importância de avaliar uma fração específica, o que corrobora com o determinado em legislação. Além disso, refinar o monitoramento da qualidade da 
água de rios durante os eventos de chuva, e avaliar os impactos visuais (aporte de material particulado) e não visuais (aporte de material dissolvido) são formas de propor avanços na gestão de recursos hídricos, bem como a efetiva aplicação de seus instrumentos. Por isso, sugere-se a realização de estudos com mais eventos de precipitação.

No que concerne à gestão de recursos hídricos, entende-se que a adequada aplicação dos instrumentos de gestão depende diretamente da identificação da fração que sintetiza os efeitos poluidores. Nesta pesquisa, identifica-se a necessidade de aprofundamento desta questão fundamentado em estratégias de monitoramento consistentes, experimentalmente mais abrangentes e que considere a dinâmica hidrológica de uma bacia de forma consistente.

\section{AGRADECIMENTOS}

Os autores agradecem ao Conselho Nacional de Desenvolvimento Científico e Tecnológico (CNPq) e a Coordenação de Aperfeiçoamento de Pessoal de Nível Superior (CAPES) pelo auxílio financeiro.

\section{REFERÊNCIAS}

American Public Health Association - APHA. (2012). Standard methods for the examination of water and wastewater (Vol. 10). Washington, DC: American Public Health Association.

Baird, C., \& Cann, M. (2011). Química ambiental (4. ed., 844 p.). Porto Alegre: Bookman.

Braga, S. M. (2013). Uma nova abordagem para integração entre quantidade e qualidade da água para a avaliação da poluição difusa (Tese de doutorado). Programa de Pós-graduação em Engenharia de Recursos Hídricos e Ambiental, Universidade Federal do Paraná, Curitiba. Recuperado em 10 de março de 2020, de https://acervodigital.ufpr.br/handle/1884/36071

Brasil. (2005, 18 de março). Resolução CONAMA Nº.357, de 17 de março de 2005. Dispõe sobre a classificação dos corpos de água e diretrizes ambientais para o seu enquadramento, bem como estabelece as condições e padrões de lançamento de efluentes, e dá outras providências. Diário Oficial [da] República Federativa do Brasil, Brasília. Recuperado em 10 de março de 2020, de http://www2.mma.gov.br/port/conama/legiabre.cfm?codlegi=459

Chini, A., Hollas, C. E., Bolsan, A., \& Treichel, H., \& Kunz, A. (2018). Centrifugação: uma alternativa de pré-tratamento para digestato? In Anais do $47^{\circ}$ Congresso Brasileiro de Engenharia Agrícola. Brasília, DF: SBEA. Embrapa Suínos e AvesArtigo em anais de congresso (ALICE).

Cipriano, F. B. G., Kozak, C., Prado, L. L., \& Fernandes, C. V. S. (2019). Consolidação de rotina analítica para quantificação de fósforo total em corpos hídricos: impactos para a gestão dos recursos hídricos. Revista de Gestão de Água da América Latina, 16(11). https://10.21168/rega.v16e13.>

Dodds, W. K., \& Smith, V. H. (2016). Nitrogen, phosphorus, and eutrophication in streams. Inland Waters, 6(2), 155-164. Recuperado em 10 de março de 2020, de https://www.tandfonline.com/doi/abs/10.5268/IW-6.2.909

Felice, J. G., Silveira, A., Isidoro, J. M. P. G., Gonçalves, F. A., \& Silva, A. M. (2018). Simulação do transporte de partículas em suspensão e de poluentes dissolvidos pelo escoamento em superfícies impermeáveis: uma contribuição ao saneamento urbano. Engenharia Sanitaria e Ambiental, 405-414.

Ferreira, D. B. (2019). Structural Best Management Practices (BMPS) and hydrological effects modelling using SWAT for urban watershed (Dissertação de mestrado). Programa de Pós-graduação em Engenharia de Recursos Hídricos e Ambiental, Universidade Federal do Paraná, Curitiba. Recuperado em 10 de março de 2020, de https://acervodigital.ufpr.br/handle/1884/62714

Instituto das Águas do Paraná - SUDERHSA. (2000). Sistema de Informação Geográfica para a Gestão de Recursos Hídricos: mapeamento do estado do Paraná. Recuperado em 26 de outubro de 2019, de http://www.aguasparana.pr.gov.br/pagina-79.html

Kozak, C. (2016). Water quality assessment and its effects on diffuse pollution considering a new water quality and quantity approach (Dissertação de mestrado). Programa de Pós-graduação em Engenharia Ambiental, Universidade Federal do Paraná, Curitiba. Recuperado em 10 de março de 2020, de https://acervodigital.ufpr.br/handle/1884/43629

Kozak, C., Fernandes, C. V. S., Braga, S. M., Prado, L. L., Froehner, S., \& Hilgert, S. (2019). Water quality dynamic during rainfall episodes: integrated approach to assess diffuse pollution using automatic sampling. Environmental Monitoring and Assessment, 191(6), 402. http://dx.doi.org/10.1007/s10661-019-7537-6

Kraal, P., Dijkstra, N., Behrends, T., \& Slomp, C. P. (2017). Phosphorus burial in sediments of the sulfidic deep Black Sea: key roles for adsorption by calcium carbonate and apatite authigenesis. Geochimica et Cosmochimica Acta, 204, 140158. http://dx.doi.org/10.1016/j.gca.2017.01.042

Lee, H., \& Lautenbach, S. (2016). A quantitative review of relationships between ecosystem services. Ecological Indicators, 66, 340-351. http://dx.doi.org/10.1016/j.ecolind.2016.02.004 
Mbabazi, J., Inoue, T., Yokota, K., \& Saga, M. (2019). Variability of particulate bioavailable phosphorus, particulate organic carbon and nitrogen in agricultural and urban rivers. Journal of Environmental Chemical Engineering, 7(3), 103086. http://dx.doi.org/10.1016/j.jece.2019.103086

MetCalf, E., Burton, F. L., Stensel, H. D., \& Tchobanoglous, G. (2003). Wastewater engineering: treatment and reuse. McGraw Hill.

Piveli, R. P., \& Kato, M. T. (2006). Qualidade das águas e poluição: aspectos físico-químicos. São Paulo: ABES.

Powrosnek, M., Kozak, C., \& Fernandes, C. V. S. (2019). Desafios analíticos da série de nitrogênio: impacto da dinâmica temporal. In Anais do XXIII Simpósio Brasileiro De Recursos Hidrícos. Foz do Iguaçú: Associação Brasileiro de Recursos Hídricos. Recuperado em 28 de abril de 2020, de http://anais.abrh.org.br/events/107

Prado, L. L. (2015). Procedimento analítico para quantificação de fósforo total por digestão ácida (S. Froehner \& R. F. Martins, informação verbal). Adaptado de "Avaliação da composição química de sedimentos do Rio Barigui na Região Metropolitana de Curitiba (2008)".

Rattan, K. J., Blukacz-Richards, E. A., Yates, A. G., Culp, J. M., \& Chambers, P. A. (2019). Hydrological variability affects particulate nitrogen and phosphorus in streams of the northern Great Plains. Journal of Hydrology: Regional Studies, 21,110-125. http://dx.doi.org/10.1016/j.ejrh.2018.12.008

Russel, J. B. (1994). Química geral (Márcia Guekezian, Trad.). São Paulo-SP: McGrall-Hill.

Salgado, A. A. (2013). Caracterização da influência de cargas poluidoras difusas na qualidade da água no córrego botafogo, Goiânia, Goiás. (Dissertação de mestrado). Programa de Pós- Graduação em Engenharia do Meio Ambiente, Universidade Federal de Goiás. Goiânia, Goiás, 2013. Recuperado em 16 de março de 2020, de https://repositorio.bc.ufg.br/tede/handle/tede/3496

Shriver, D. F., \& Atkins, P. W. (2003). Química inorgânica (3. ed., 816 p.). Editora Bookman.

Silva, K. C., \& Poleto, C. (2017). Drenagem urbana sustentável: aspectos hidrológicos, influência dos sedimentos e o reequilíbrio dos ciclos naturais. In Anais do $2^{\circ}$ Congresso Internacional de Hidrossedimentologias. Foz do Iguaçu: Interciência. Recuperado em 10 de março de 2020, de https://www.lume.ufrgs.br/bitstream/handle/10183/170574/001025262.pdf?sequence=1

Skoog, D. A., West, D. M., \& Holler, F. J. (2006). Fundamentos de química analítica (8. ed., Vol. 2). São Paulo, SP: Thomson Learning.

Smith, D. R., Jarvie, H. P., \& Bowes, M. J. (2017). Carbon, nitrogen, and phosphorus stoichiometry and eutrophication in River Thames tributaries, UK. Agricultural \& Environmental Letters, 2(1), http://dx.doi.org/10.2134/ael2017.06.0020

Sperling, M. V. (1996). Introdução à qualidade das águas e ao tratamento de esgotos (Vol. 1.). Universidade Federal de Minas Gerais.

Stein, L. Y., \& Klotz, M. G. (2016). The nitrogen cycle. Current Biology, 26(3), R94-R98.

\section{Contribuições}

Mayara Powrosnek: foi responsável por toda execução do trabalho em laboratório, processamento e análise dos dados, bem como a elaboração deste texto.

Caroline Kozak: foi responsável pela co-orientação e supervisão do desenvolvimento deste trabalho, auxiliando nas atividades de campo para coleta de amostras, auxílio no laboratório, processamento e análise dos dados e elaboração deste texto.

Luciane Lemos do Prado: foi responsável pela elaboração do planejamento experimental deste trabalho, bem como auxílio no laboratório, processamento de dados e elaboração deste texto.

Cristovão Vicente Scapulatempo Fernandes: foi o professor orientador deste trabalho, auxiliando na viabilidade de espaço e recursos, planejamento experimental, atividades de campo para coleta das amostras e elaboração deste texto. 


\section{APÊNDICE A}

Este material contém informações adicionais sobre os materiais e métodos utilizados que contribuem para o completo entendimento da proposta deste trabalho, bem como informações complementares dos dados coletados e processados.

Os dados são apresentados da seguinte forma

1. Materiais e Métodos

a. Ponto de amostragem BA1 (Figura 1A)

b. Ponto de amostragem BA2 (Figura 2A)

c. Diferenças nas seções transversais (Figura 3A)

d. Curvas de descarga

e. Limite de detecção e Limite de Quantificação

i. Nitrogênio (Figura 4A)

ii. Fósforo (Figura 5A)

2. Resultados

a. Datas, horas, nível e vazões no momento da coleta das amostras (Tabela 2A)

b. Concentrações de nitrogênio e fósforo medidas em cada amostra do evento de chuva analisada, para as frações dissolvida e particuladas em ambos os pontos de monitoramento (Tabela 3A).

\section{MATERIAIS E MÉTODOS}

a. Ponto de amostragem BA1: é possível observar na imagem a existência de uma estação pluviométrica, que é de onde os dados de chuva foram coletados.
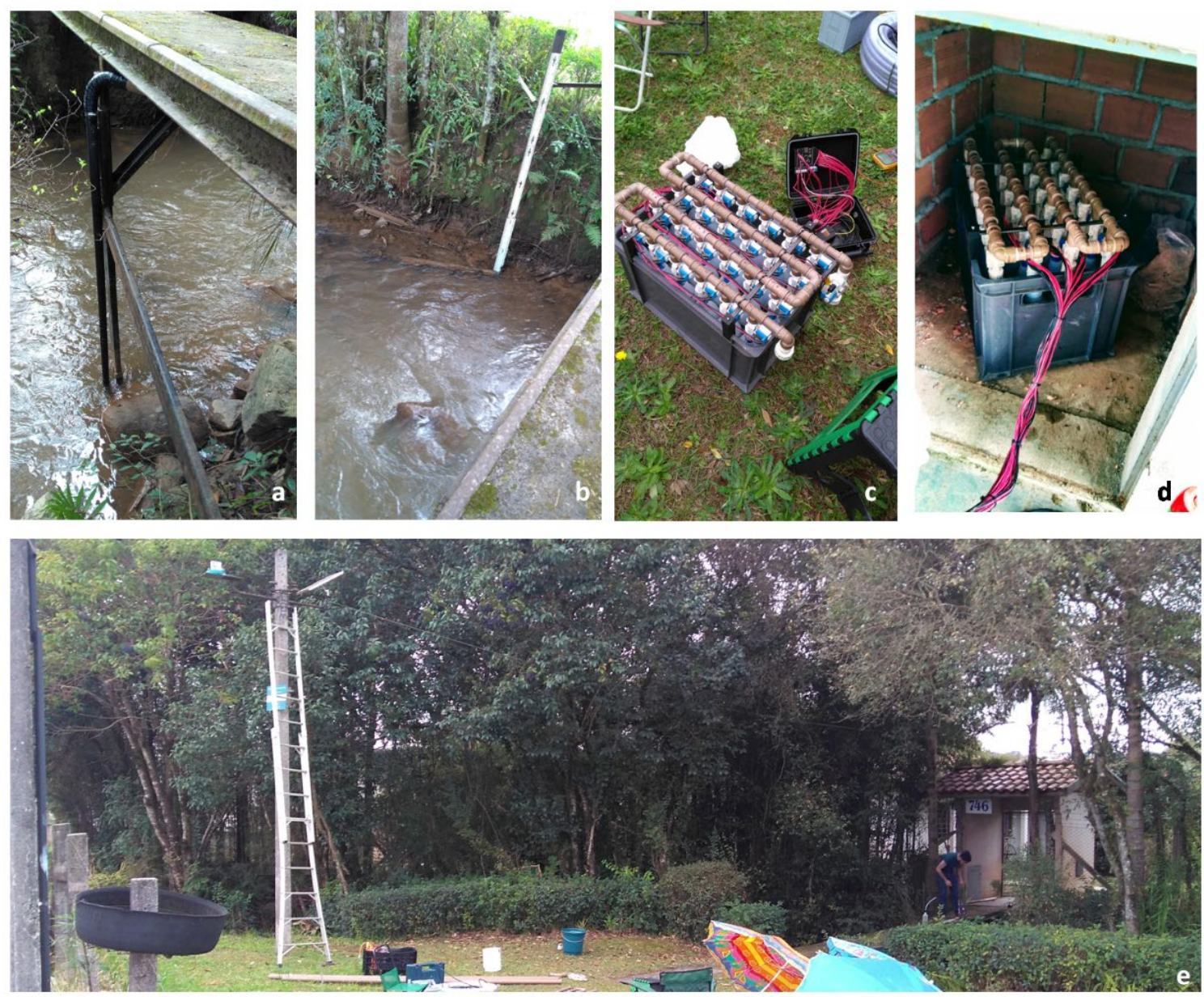

Figura 1A. Ponto de monitoramento BA1. (a) Estrutura de coleta de dados e amostras; (b) Régua para medição da altura da coluna d'água; (c) Amostrador automático; (d) Local de armazenamento do amostrador; (e) Local de monitoramento como um todo. 
b. Ponto de amostragem BA2: a estação pluviométrica utilizada para a aquisição de dados de chuva encontra-se a cerca de 20 metros do local onde a estrutura apresentada está instalada.
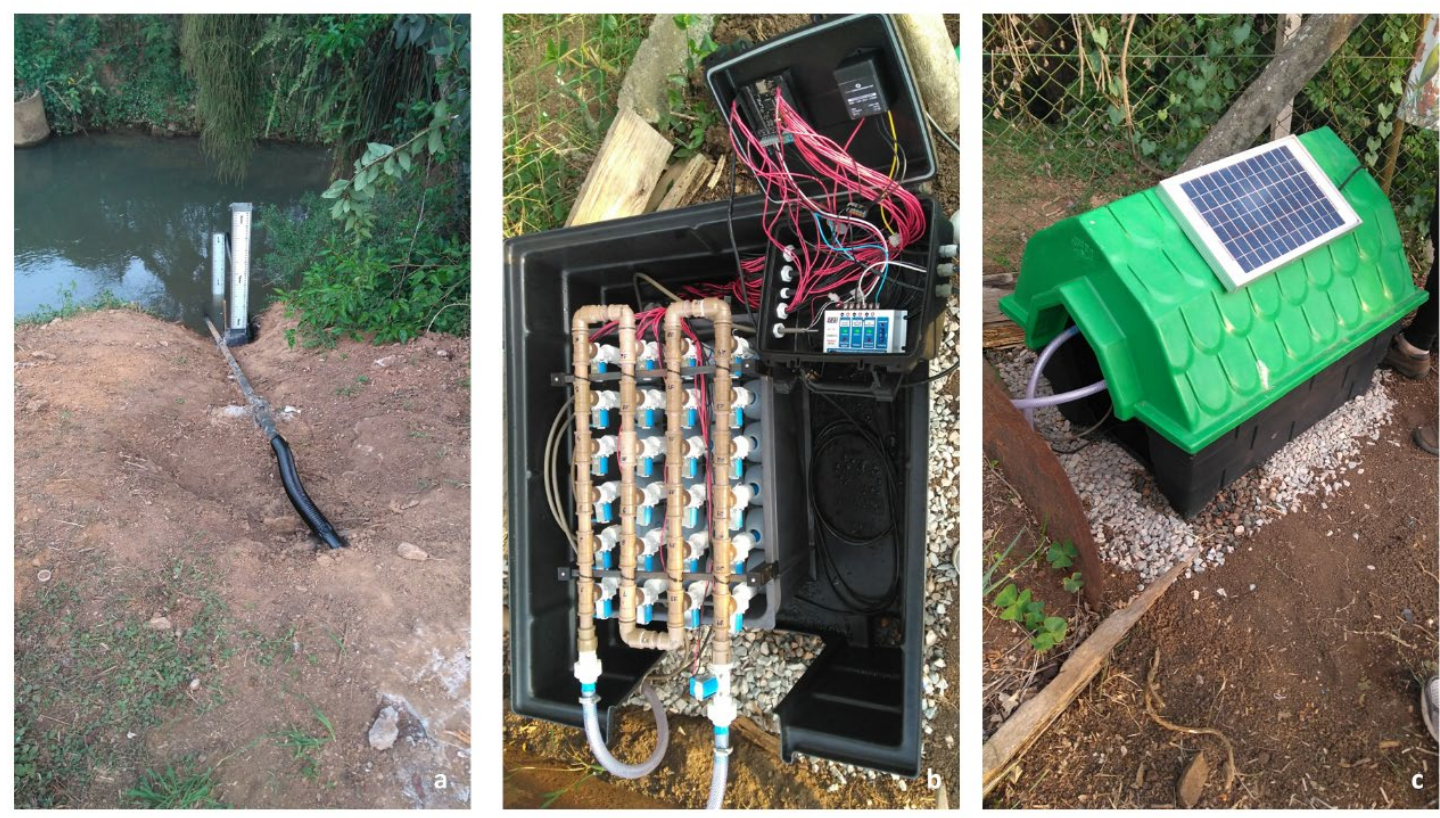

Figura 2A. Ponto de monitoramento BA2: (a) Régua para medição da altura da coluna d'água e estruturas de armazenamento do sensor de nível e coleta de amostras; (b) Amostrador Automático; (c) Local de armazenamento do amostrador automático, também alimentado por energia solar.

c. Diferenças nas seções transversais

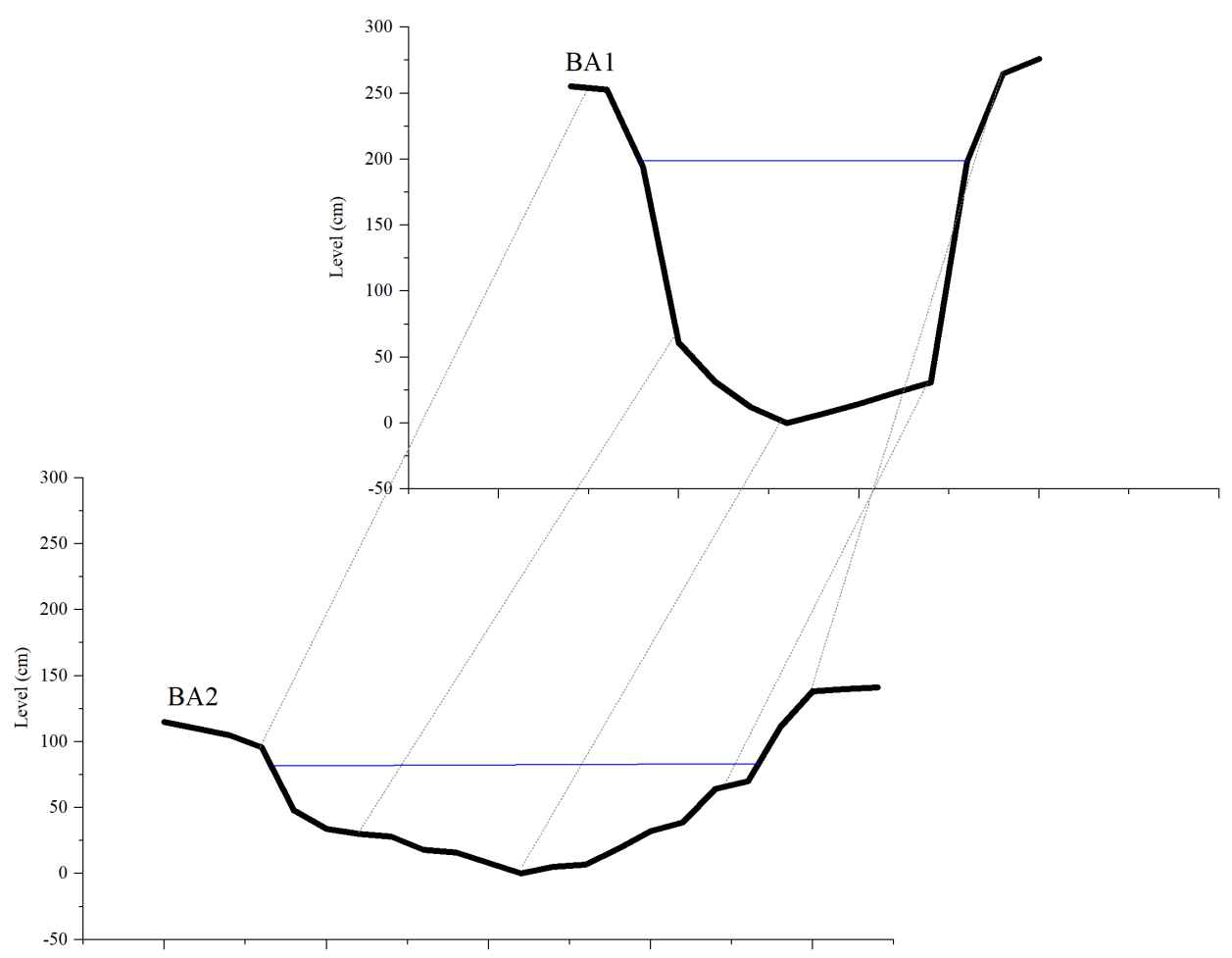

Figura 3A. Representação das diferentes seções transversais monitoradas neste trabalho. 
d. Curvas de descarga

Curva de descarga do ponto BA1: $Q=3,1517 *(h+0,07941)^{1,0907}$

Curva de descarga do ponto BA2: $Q=0,619 * e^{1,554^{*} h}$

Onde: $\mathrm{Q}$ é a vazão $\left(\mathrm{m}^{3} / \mathrm{s}\right)$ e h é a altura da coluna d'água $(\mathrm{m})$

e. Limite de detecção e Limite de Quantificação

i. Nitrogênio

A imagem abaixo se refere a curva de calibração do nitrogênio total para os métodos de Digestão por Persulfato (4500-N-C), seguido por redução em coluna de Cd-Cu (4500- $\mathrm{NO}_{3}$-E) e então quantificado pelo método colorimétrico (4500-NO2-B), como determinado por APHA (2012).

\section{Curva Nitrogênio Total}

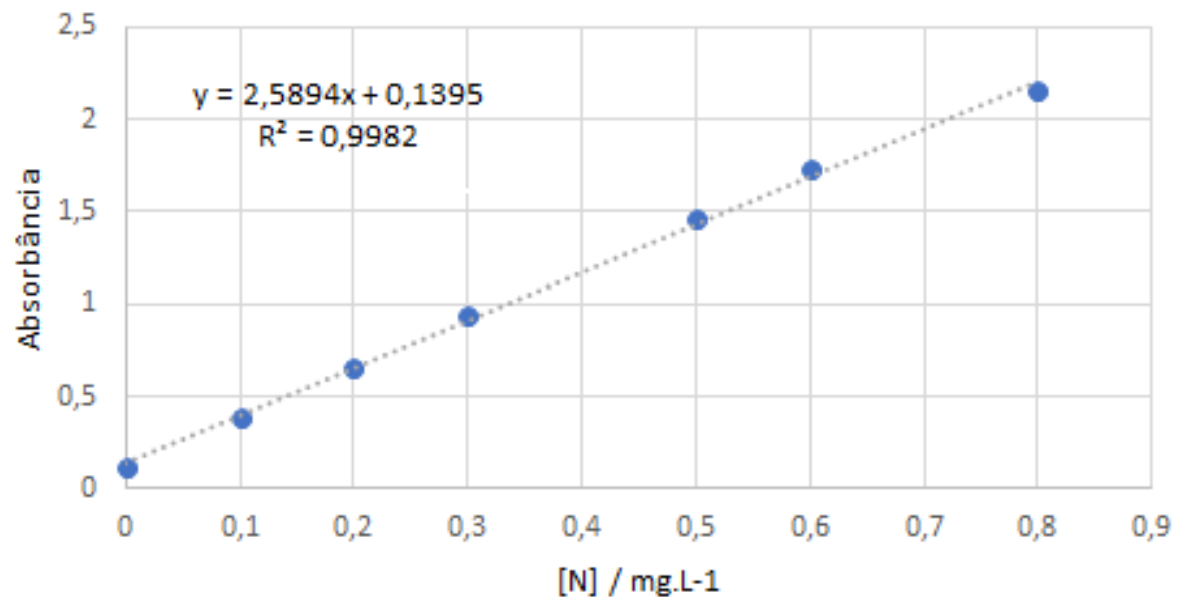

Figura 4A. Curva de calibração para a quantificação de Nitrogênio total, variando de $0 \mathrm{mg}$. $\mathrm{L}^{-1}$ até $0,8 \mathrm{mg} \cdot \mathrm{L}^{-1}$.

Foi realizado uma curva de calibração de $0 \mathrm{mg} \cdot \mathrm{L}^{-1}$ até $0,8 \mathrm{mg} \cdot \mathrm{L}^{-1}$. Observa-se que o método possui bom coeficiente de correlação linear $\mathrm{R}^{2}=0,99$. Assim, os limites são:

$\mathrm{LD}=3 \frac{\sigma_{\text {branco }}}{\alpha_{\text {curva }}}=3 \frac{0,0031}{2,5894}=0,0036 \mathrm{mg} \cdot \mathrm{L}^{-1}$

$\mathrm{LQ}=10 \frac{\sigma_{\text {branco }}}{\alpha_{\text {curva }}}=10 \frac{0,0031}{2,5894}=0,0120 \mathrm{mg} \cdot \mathrm{L}^{-1}$

ii. Fósforo

Para o fósforo foram realizadas duas curvas de calibração: (i) de baixas concentrações, variando de 0 mg. $\mathrm{L}^{-1}$ a $0,15 \mathrm{mg} \cdot \mathrm{L}^{-1}$, e (ii) altas concentrações, variando de $0 \mathrm{mg} \cdot \mathrm{L}^{-1}$ a $1,5 \mathrm{mg} \cdot \mathrm{L}^{-1}$. Essa divisão foi realizada devido à diferença de inclinação das retas e para garantir a correta quantificação de valores baixos de fósforo. Tais considerações são abordadas no estudo de Cipriano et al. (2019). As imagens abaixo se referem às curvas de calibração de baixa e alta concentrações, respectivamente, para o método proposto por Prado (2015), disponível em Cipriano et al., (2019), para digestão das amostras, seguido pelo método colorimétrico do ácido ascórbico (4500-P-E) proposto por APHA (2012). 


\section{Curva Baixas Fósforo Total}

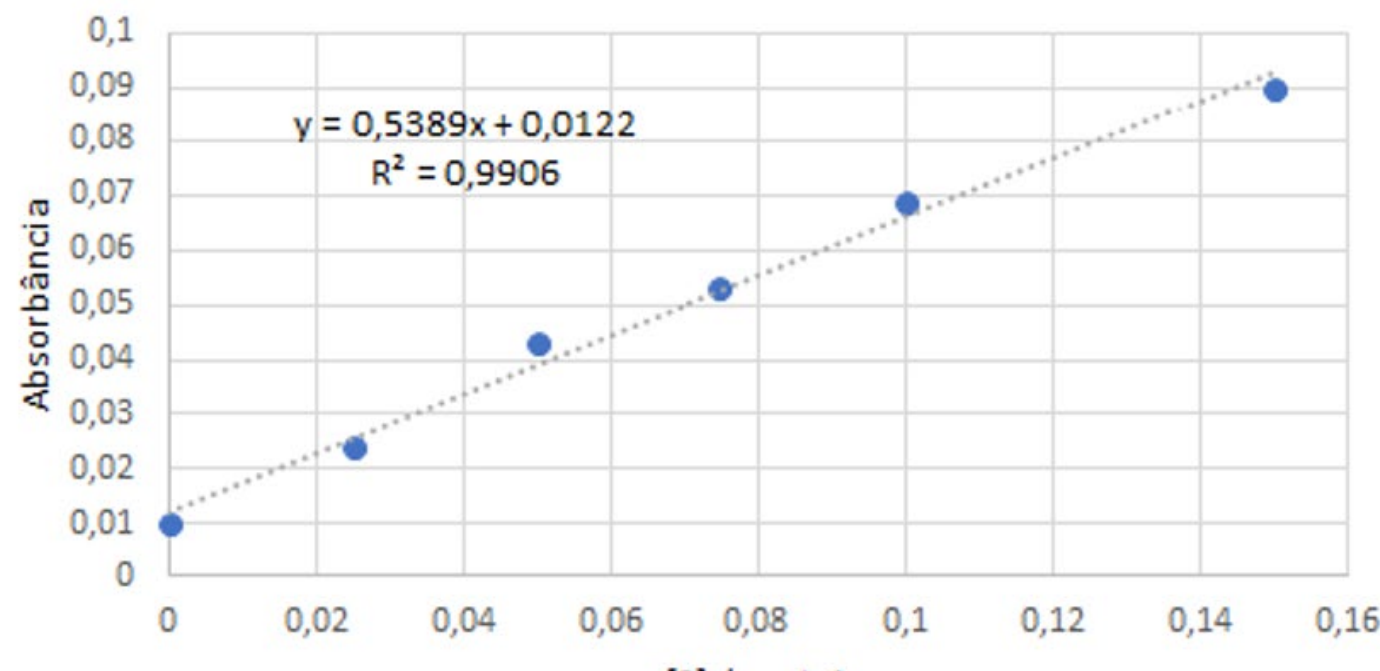

[P] / mg.L-1

\section{Curva Altas Fósforo Total}

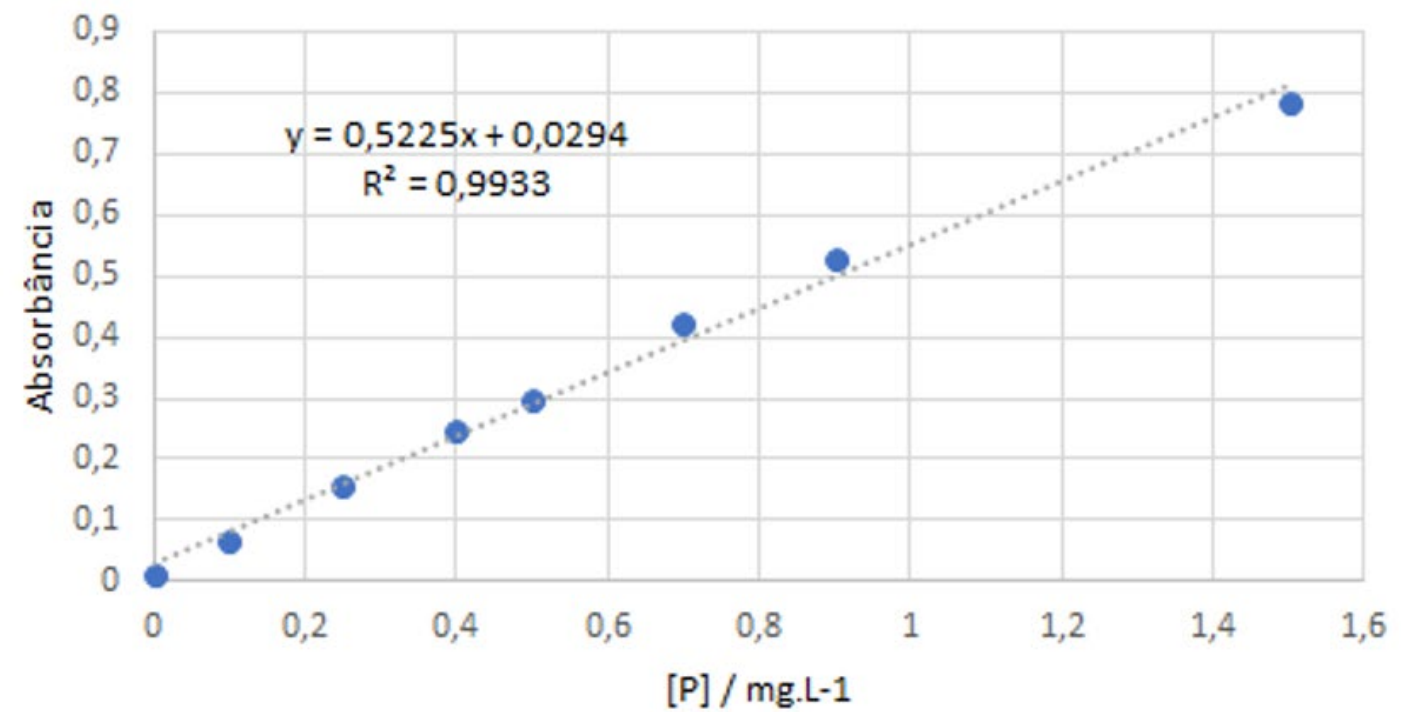

Figura 5A. Curvas de calibração para concentrações baixas (acima) variando de 0 mg.t-1 a 0,15 mg.L-1, e de concentrações altas (abaixo), variando de $0 \mathrm{mg} \cdot \mathrm{L}^{-1}$ a $1,5 \mathrm{mg} . \mathrm{L}^{-1}$ de fósforo total.

Ambas curvas de calibração apresentam bom coeficiente de correlação linear, com $\mathrm{R}^{2}=0,99 \mathrm{em}$ ambos, evidenciando a confiabilidade dos dados analíticos gerados neste trabalho. Assim, os limites para a curva de concentração baixa e alta são:

Tabela 1A. Limites de detecção e quantificação para as curvas de baixas e altas concentrações de fósforo total.

\section{Curvas de Concentração Baixa}

\begin{tabular}{c|c}
\hline $\mathrm{LD}=3 \frac{\sigma_{\text {branco }}}{\alpha_{\text {curva }}}=3 \frac{0,0010}{0,5389}=0,005 \mathrm{mg} \cdot \mathrm{L}^{-1}$ & $\mathrm{LD}=3 \frac{\sigma_{\text {branco }}}{\alpha_{\text {curva }}}=3 \frac{0,0010}{0,5225}=0,006 \mathrm{mg} \cdot \mathrm{L}^{-1}$ \\
\hline $\mathrm{LQ}=10 \frac{\sigma_{\text {branco }}}{\alpha_{\text {curva }}}=10 \frac{0,0010}{0,5389}=0,018 \mathrm{mg} \cdot \mathrm{L}^{-1}$ & $\mathrm{LQ}=10 \frac{\sigma_{\text {branco }}}{\alpha_{\text {curva }}}=10 \frac{0,0010}{0,5225}=0,019 \mathrm{mg} \cdot \mathrm{L}^{-1}$ \\
\hline
\end{tabular}




\section{RESULTADOS}

Tabela 2A. Data, hora, nível e vazão do momento da coleta das amostras analisadas.

\begin{tabular}{|c|c|c|c|c|}
\hline \multirow{2}{*}{ Data } & \multicolumn{4}{|c|}{ Ponto BA1 } \\
\hline & Hora & Amostra & Nível (cm) & Vazão $\left(\mathrm{m}^{3} / \mathrm{s}\right)$ \\
\hline $03 / 10 / 2018$ & 11:06:01 & 1 & 32,5 & 1,17 \\
\hline $03 / 10 / 2018$ & $11: 16: 01$ & 2 & 68,8 & 2,36 \\
\hline $03 / 10 / 2018$ & $12: 14: 01$ & 3 & 79,5 & 2,72 \\
\hline $03 / 10 / 2018$ & 13:02:01 & 4 & 48,6 & 1,69 \\
\hline $03 / 10 / 2018$ & $13: 17: 01$ & 5 & 38,3 & 1,36 \\
\hline $03 / 10 / 2018$ & 19:44:01 & 6 & 18,0 & 0,72 \\
\hline \multirow{2}{*}{ Data } & \multicolumn{4}{|c|}{ Ponto BA2 } \\
\hline & Hora & Amostra & Nível (cm) & $\operatorname{Vazão}\left(\mathrm{m}^{3} / \mathrm{s}\right)$ \\
\hline $03 / 10 / 2018$ & 14:03:01 & 1 & 73,7 & 1,95 \\
\hline $03 / 10 / 2018$ & $15: 12: 01$ & 2 & 93,0 & 2,63 \\
\hline $03 / 10 / 2018$ & $20: 10: 01$ & 3 & 73,8 & 1,95 \\
\hline $03 / 10 / 2018$ & $21: 33: 01$ & 4 & 63,8 & 1,67 \\
\hline $04 / 10 / 2018$ & 02:19:02 & 5 & 56,7 & 1,49 \\
\hline $04 / 10 / 2018$ & 09:13:00 & 6 & 50,9 & 1,37 \\
\hline
\end{tabular}

Tabela 3A. Concentrações de $\mathrm{N}$ e P em cada amostra coletada durante o evento de chuva, em ambos os pontos de monitoramento

\begin{tabular}{|c|c|c|c|c|c|c|c|c|}
\hline \multicolumn{9}{|c|}{ Ponto BA1 } \\
\hline & \multicolumn{4}{|c|}{ Nitrogênio (mg L-1) } & \multicolumn{4}{|c|}{ Fósforo (mg L-1) } \\
\hline & $D_{F}$ & $P_{F}$ & $\mathrm{D}_{\mathrm{C}}$ & $\mathbf{P c}_{\mathrm{C}}$ & $\mathbf{D F}_{\mathrm{F}}$ & $\mathbf{P}_{\mathbf{F}}$ & $\mathbf{D}_{\mathbf{C}}$ & $\mathbf{P C}_{\mathrm{C}}$ \\
\hline BA1_1 & 4,69 & 0,16 & 4,55 & 3,73 & 0,04 & 0,92 & 0,12 & 1,12 \\
\hline BA1_2 & 2,79 & 1,35 & 3,59 & 3,08 & 0,03 & 0,56 & 0,03 & 0,53 \\
\hline BA1_3 & 3,22 & 0,32 & 4,22 & 3,79 & 0,04 & 1,22 & 0,07 & 1,38 \\
\hline BA1_4 & 2,49 & 0,17 & 4,42 & 2,80 & 0,04 & 1,02 & 0,04 & 1,16 \\
\hline BA1_5 & 3,82 & 0,14 & 4,79 & 2,69 & 0,04 & 0,85 & 0,03 & 1,04 \\
\hline BA1_6 & 1,78 & 0,35 & 3,26 & 1,86 & 0,02 & 0,24 & 0,04 & 0,32 \\
\hline \multicolumn{9}{|c|}{ Ponto BA2 } \\
\hline & \multicolumn{4}{|c|}{ Nitrogênio (mg L-1) } & \multicolumn{4}{|c|}{ Fósforo (mg L-1) } \\
\hline & $\mathrm{DF}_{\mathrm{F}}$ & $\mathrm{P}_{\mathrm{F}}$ & $\mathrm{DC}_{\mathrm{c}}$ & $\mathrm{Pc}_{\mathrm{C}}$ & $\mathrm{DF}_{\mathrm{F}}$ & $\mathrm{P}_{\mathrm{F}}$ & $\mathrm{Dc}_{\mathrm{c}}$ & $\mathrm{P}_{\mathrm{C}}$ \\
\hline BA2_1 & 3,60 & 0,34 & 1,87 & 1,97 & 0,05 & 1,14 & 0,13 & 1,37 \\
\hline BA2_2 & 4,07 & 2,24 & 2,08 & 2,73 & 0,05 & 1,82 & 0,32 & 2,47 \\
\hline BA2_3 & 3,31 & 0,39 & 1,61 & 3,14 & 0,08 & 1,37 & 0,14 & 1,66 \\
\hline BA2_4 & 3,39 & 0,28 & 1,50 & 2,67 & 0,05 & 1,22 & 0,15 & 1,44 \\
\hline BA2_5 & 2,54 & 0,45 & 1,32 & 1,44 & 0,07 & 0,64 & 0,13 & 0,87 \\
\hline BA2_6 & 4,38 & 0,33 & 2,01 & 3,66 & 0,10 & 1,76 & 0,17 & 2,53 \\
\hline
\end{tabular}

Nota: $\mathrm{D}_{\mathrm{F}}=$ fração dissolvida após filtração em membrana de $0,45 \mu \mathrm{m}$. $\mathrm{P}_{\mathrm{F}}=$ fração particulada retida no filtro de $0,45 \mu \mathrm{m}$. $\mathrm{D}_{\mathrm{C}}=$ fração dissolvida ou correspondente ao sobrenadante do centrifugado. $\mathrm{P}_{\mathrm{C}}=$ particulado ou sólido decantado do centrifugado. 